\title{
TEMPERATURE: AN EASY, INEXPENSIVE, BUT USEFUL TOOL FOR MAPPING KARST SPRING HABITATS
}

Joe C. Yelderman Jr.

Baylor University, One Bear Place 97354,Waco, Texas 76798,_USA, joe_yelderman@baylor.edu

\section{Stephanie S. Wong}

Baylor University, One Bear Place 97354, Waco, Texas 76798, USA, stephanie_wong@baylor.edu

\section{Abstract}

Karst aquifer spring habitats around the world support a diversity of specially-adapted, unusual, or rare aquatic flora and fauna. Temperature is one of the most appealing attributes of spring habitats because the consistent groundwater flow associated with springs maintains more constant temperatures than surface flows susceptible to seasonal and diurnal fluxes. Karst aquifers commonly have specific point-source discharge from fractures causing more abrupt changes in local water conditions compared to discharge from granular sand aquifers. Mapping the temperature distribution associated with karst spring discharge can help delineate the most important habitat areas associated with spring-dependent organisms. The downtown spring complex in the Northern Segment of the Edwards Balcones Fault Zone aquifer in central Texas is home to several spring-dependent organisms including an endemic salamander, Eurycea chisolmensis, that is federally listed as "threatened". Temperatures were measured with a Solinst TLC meter and with a hand-held infrared camera. The Solinst TLC meter measured temperature rapidly and the FLIR infrared camera provided dramatic visual images while documenting dynamics associated with spring discharge temperatures. The temperature data were comparable to specific conductance data indicating that temperature could be used to map areas of basic water chemistry changes in local systems. Aquatic plant assemblages correlated well with the areas delineated by temperature gradients. Overall, temperatures in Salado Creek and the associated spring orifices of the downtown spring complex showed a relationship between temperature and preferred habitat for spring organisms. The results indicated that temperature was an effective parameter to use in spring habitat studies due to its high importance to spring dependent organisms, low cost, and ease of collection.

\section{Introduction}

The Northern Segment of the Edwards Balcones Fault Zone (BFZ) aquifer is a valued water resource due to its high capacity to transmit water and its rapid recharge. The latter characteristic is due to thin soils over fractured bedrock. The former characteristic of high capacity is related to the widening of fractures resulting from dissolution of the carbonate rocks along major flow paths. The same dissolution process also produces karst features such as caves and sinkholes. The large openings characteristic of karst also allows a variety of aquatic organisms including isopods, gastropods, and salamanders to live in portions of the aquifer. Opportunistic organisms can enter the aquifer through the large openings and take advantage of the nearly constant groundwater temperature insulated from climatic extremes. Such is the case of the federally threatened Salado salamander Eurycea chisolmensis. The Salado salamander occurs in several places within the Salado Creek basin and may occur outside the basin (Devitt et al., 2019). The most important task in preserving the threatened Salado Salamander is maintaining spring flow as water demands in the aquifer increase. The Clearwater Underground Water Conservation District currently manages the Edwards aquifer in Bell County and has approved a Desired Future Condition of $0.05 \mathrm{~m}^{3} / \mathrm{s}$ minimal spring flow in the downtown area. The second concern for the salamander is maintaining its critical habitat. A major component of the critical habitat is suitable water temperatures. Bowles et al. (2006) found salamander densities were negatively correlated with the standard deviation of water temperature for the nearby Jollyville Plateau salamander (Eurycea tonkawae) which also occurs in the northern segment of the Edwards Balcones Fault Zone aquifer. This study focuses on water temperature associated with Big Boiling (Brune, 1981) and Side (Wong, 2015) springs in the downtown Salado spring complex (Figures 1 and 2). Salado Salamanders have been found in the spring runs of discharging springs and using temperature to map habitat provides an example of how temperature measurements can aid in understanding habitat location.

\section{Setting}

Salado Creek is a shallow perennial stream approximately 5-10 meters wide flowing primarily on limestone bedrock of the Edwards formation with limestone gravel 
alluvium along its floodplain. Moderate baseflow of 0.2$0.6 \mathrm{~m}^{3} / \mathrm{s}$ is the norm in the downtown Salado area but flash floods are common (Williams CR, 2013). The shallow nature of the stream results in seasonal temperature fluctuations, but major spring discharge points mitigate water temperatures in certain areas. Salamander habitat begins in the stable groundwater temperatures at spring discharge points and extends until surface exposure significantly changes the temperature or surface water mixes with the groundwater and changes the temperature through dilution.

The groundwater/stream interaction generally behaves in a more laminar than turbulent fashion even though the flow is technically turbulent in the stream. Groundwater hugs the near bank for some distance downstream, extending the thermally stable range in the channel. This potential habitat exhibits vegetation that is thought to be suitable for the salamander and can be mapped using a temperature/specific conductance probe.

\section{Methods}

Cross Sections

Temperatures were measured in the spring orifices as an endpoint for aquifer groundwater temperature and then across the widths of Salado Creek at regular intervals for three cross sections to use as interpretive profiles. Data were collected in the spring (April) and the sum-
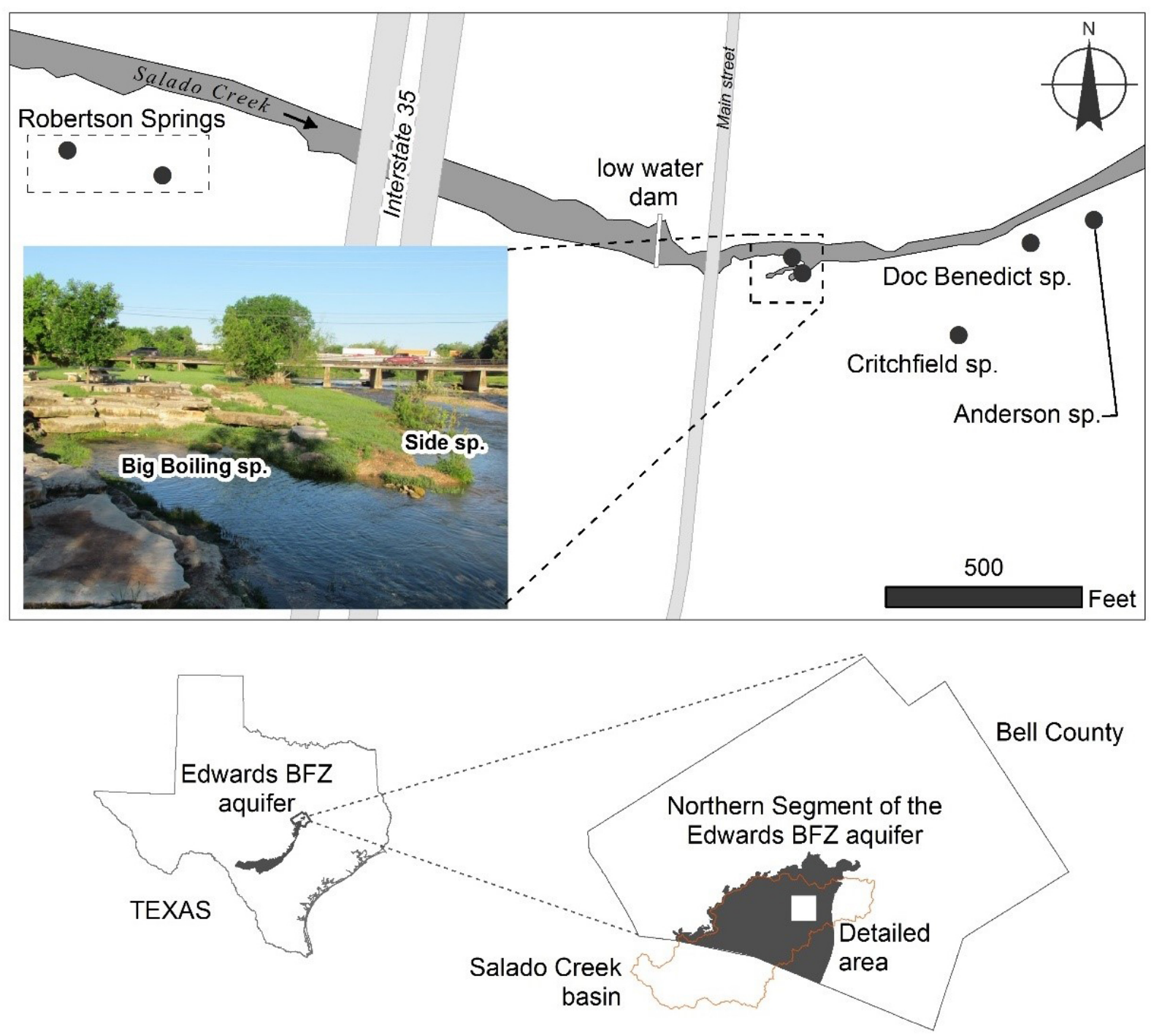

Figure 1. Map of the study setting showing key locations. The study is focused on Big Boiling and Side springs in the downtown Salado spring complex. The spring complex is located in the Northern Segment of the Edwards Balcones Fault Zone aquifer. 


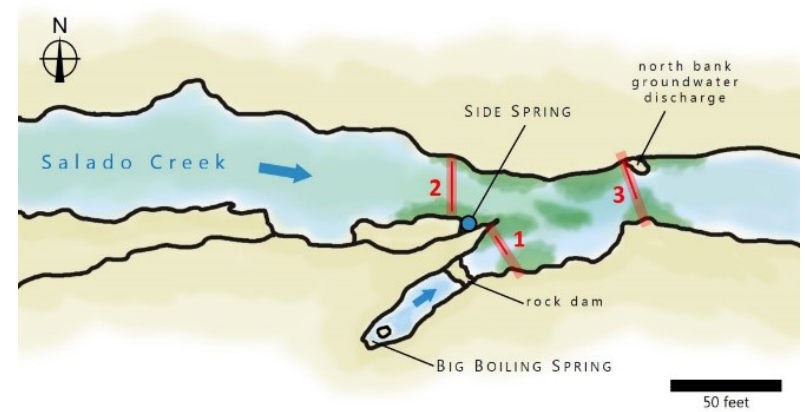

Figure 2. Diagram of Salado Creek showing key features. Cross-section locations are indicated by the red lines and labelled 1 . 2 , and 3.The green areas represent aquatic vegetation; primarily watercress.

mer (July) to represent a period of minimal temperature difference and maximum temperature difference.

All three cross-sections were taken perpendicular to flow direction (Figure 2). The measured parameters included: depth in feet (ft.), temperature in degrees Celsius $\left({ }^{\circ} \mathrm{C}\right)$, specific conductance in micro-Siemens $(\mu \mathrm{S} / \mathrm{cm})$, and flow in feet per second (fps). Measurements were made across the creek using stadia rod or reel tape laid across the channel width. Depth was measured using a metal yard stick. Temperature and specific conductance were measured using a Solinst TLC meter (Solinst Model 107 TLC Meter; Solinst Canada Ltd., Georgetown, Ontario). Flow was measured using a Global Water flow meter (Global Water Instrumentation, College Station, Texas) or SonTek Flowtracker (SonTek, San Diego, California), and the discharge for each cross section was determined using the following equations:

$$
Q=\sum q_{x}
$$

where

$$
q_{x}=\frac{\left(v_{x} d_{x} w_{x}\right)}{2}
$$

where $\mathrm{Q}$ is the total discharge for a given cross section and is equal to the sum of each of the partial discharges $\left(q_{x}\right)$ in cubic feet per second (cfs), $v_{x}$ is the measured flow velocity in feet per second (fps) at interval $\mathrm{x}, \mathrm{d}_{\mathrm{x}}$ is the measured depth in feet, and $\mathrm{w}_{\mathrm{x}}$ is the width of interval $\mathrm{x}$ in feet (equations modified from Michaud, 1991).

The specific conductance measurements were made in the natural water environment without the use of a stilling well or container, and without filtering the water. The water was very clear (spring flow and base flow conditions) but was flowing briskly except near the stream banks.
The three cross-sections were located in Salado Creek (Figure 2): within the spring flow of Big Boiling Spring (cross section one), in Salado Creek upstream of the confluence of Big Boiling Spring (cross section two), and in Salado Creek downstream of the confluence of Big Boiling Spring (cross section three).

\section{Imagery}

A FLIR E5 infrared camera was also used to document temperature patterns at the GW/SW interface. The camera was hand-held and the settings that did not vary included the emissivity (0.95) and the reflected temperature $\left(20^{\circ} \mathrm{C}\right)$. Distance was set to 33 feet as a default value but was changed when appropriate and either measured or estimated to give the best apparent results. Although the lock mode for the temperature scale was used on occasion the auto setting was used as the default because it provided the greatest contrast. The Hot Spot or Cold Spot settings were used for direct temperature readings from the hand-held camera. The camera was set to take a digital photo and a thermal image simultaneously. The thermal image used the rainbow color pattern and the Thermal MSX image mode.

\section{Results}

\section{Cross Sections}

Cross-section one is characterized by unusual consistency in temperature and specific conductance (Figure 3). Steady depth and temperature values are understandable for spring flow in the landscaped, un-shaded nature of the Big Boiling Spring pool and channel due to the discharge volume and its regional nature. Luhmann et al. (2011) found the temperature patterns in karst springs in southeastern Minnesota may vary depending upon the characteristics of the flow systems. The data from Big Boiling Spring exhibits the characteristics of a thermally effective temperature pattern (Luhmann et al., 2011) The slight changes in specific conductance may be the result of variability in flow velocities that could affect the reading. Similar specific conductance values suggest a single source of water; in this setting it is groundwater discharging from Big Boiling Spring. Furthermore, specific conductance values are similar to those measured at the Stagecoach Inn Cave, located to the south and upgradient with regard to groundwater flow. The similar specific conductance values suggest that Big Boiling Spring and the Stagecoach Inn Cave are part of the same groundwater system. 

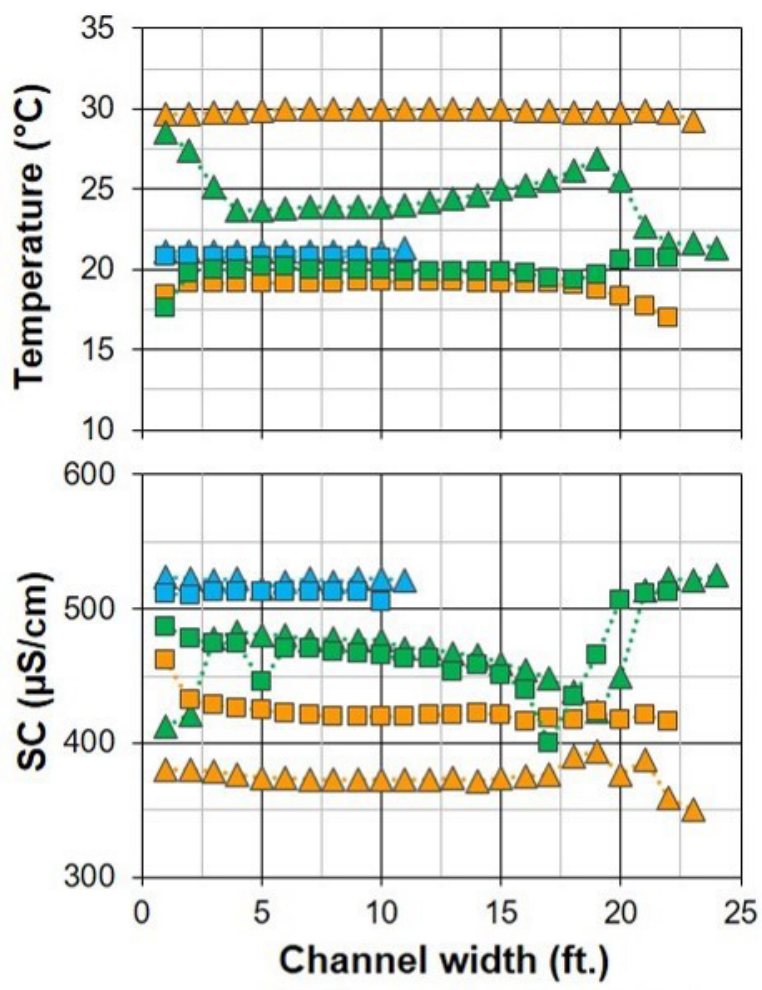

\begin{tabular}{l}
$\begin{array}{l}\text { July 30,2013 } \\
\text { CS 1: Big Boiling spring-run }\end{array}$ \\
$\square$ April 19,2014 $\quad$ CS 2: upstream of Big Boiling \\
\hline$\square$ CS 3: downstream of Big Boiling
\end{tabular}

Figure 3. Temperature and specific conductance data for cross sections 1-3 at two time periods. Note the consistency of the Big Boiling Spring temperatures and specific conductance, and the effect of the spring water on the downstream temperatures and conductivity in the creek. The cross section is oriented looking upstream and left to right is south to north.

Cross-section two is located in the natural channel of Salado Creek. The cross-section is consistently shallow, with warm water in July that is characterized by lower specific conductance than cross-section one. Temperature and specific conductance values were again fairly consistent across the section. The variation in temperature and specific conductance near the north bank (feet 18-23) are the result of very shallow, muddy conditions. Higher July temperature and lower specific conductance values than those measured at cross-section 1 suggest that flow in Salado Creek upstream of Big Boiling Spring is dominated by streamflow rather than any nearby direct groundwater discharge. Although flow in Salado Creek during these observations was dominated by baseflow from groundwater, a low-water dam immediately up- stream is partly responsible for increased temperatures and lower specific conductance.

Cross-section three is located in the natural channel of Salado Creek, downstream of the confluence with Big Boiling Spring. Temperature and specific conductance values at this location show more variability than crosssections one or two. This is to be expected since crosssection three is below the confluence of the spring and stream flow. Temperature and specific conductance at this location are intermediate values of those measured at cross-sections one and two (Figure 3), suggesting a mixing of stream water (represented by cross-section two) and groundwater discharging from Big Boiling Spring on the south side of the channel (represented by cross-section one). The July temperature rises and specific conductance decreases from the south to the north in the middle section as more surface water influences the total water flow. A probable groundwater discharge on the north side of the channel at the end of cross-section three is likely responsible for the change in temperature and specific conductance. Similar temperature and specific conductance values also suggest a groundwater connection between the two discharge points (that is, Big Boiling Spring and the north bank discharge point). Such a connection has been confirmed through dye tracing (Wong SS, 2015).

\section{Imagery}

April. A digital photograph of Side Spring discharge shows a very small delta of sediment, but it is impossible to discern the groundwater impact on the stream (Figure 4) using the digital photo image. The impact of Side spring is hypothesized to be small because of the flow ratio when compared to Salado Creek. Discharge from Side Spring ranges between $0.05-0.2 \mathrm{~m}^{3} / \mathrm{s}$ and enters Salado Creek which normally flows from $10-20 \mathrm{~m}^{3} / \mathrm{s}$. The thermal infrared camera documented the impact of Side Spring and when compared to the digital photo the impact appears greater than the area of the small delta but the warmer water from the spring flows laterally along the downstream near bank (Figure 4). Side Spring discharges slightly above the normal water line and Salado Salamanders have been found in the small spring run. Although no salamanders have been found in the creek along the bank, there is a potential for habitat based upon temperature. The temperature measured in the spring was $21^{\circ} \mathrm{C}$ while the camera measured a temperature of $21.8^{\circ} \mathrm{C}$ using the Hot Spot feature of the camera. 


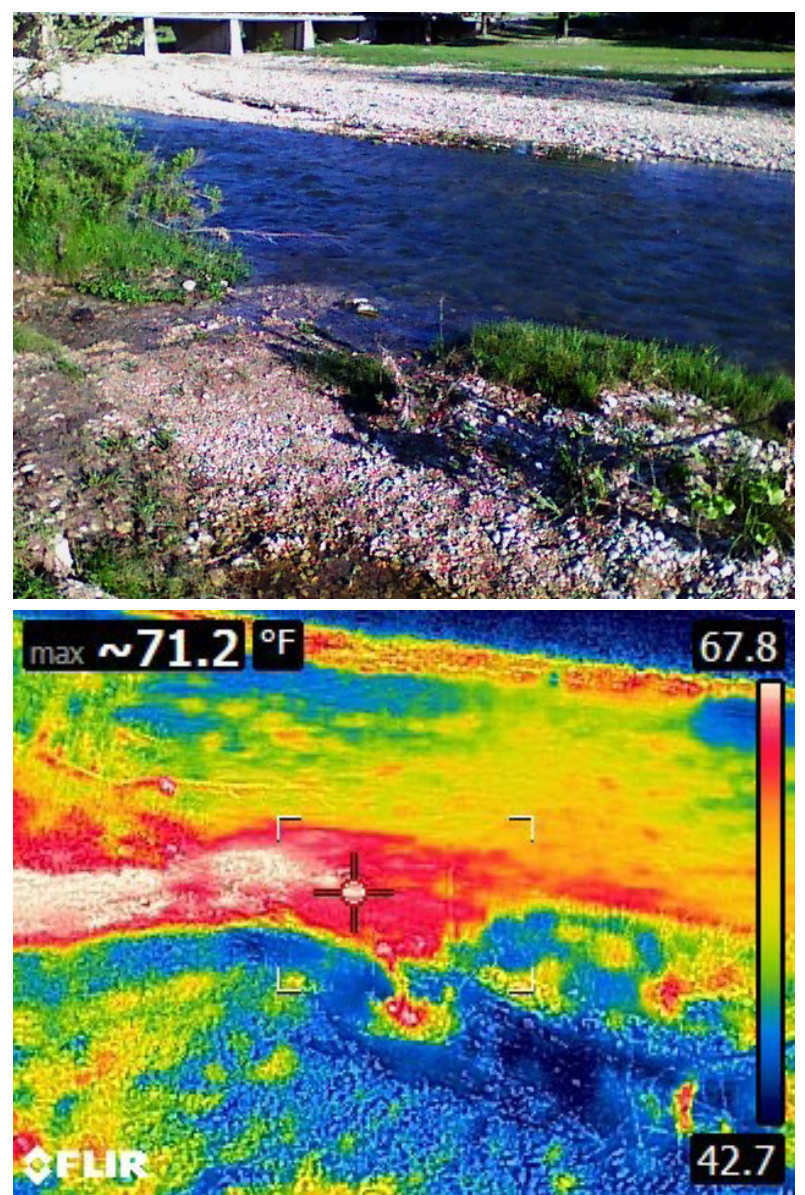

Figure 4. Images of Side Spring April 2, 2016, 8:33 a.m. The top image is a digital photo of Side Spring discharge into Salado Creek and the bottom image is the thermal image of Side Spring showing warmer groundwater (red colors) entering Salado Creek and continuing downstream along the bank.

August. Images of Side Spring August 10, 2016, 4:57 p.m. taken at a different angle, using a different scale, and using the Cold Spot feature show a similar, but slightly different pattern than the one observed in April. The digital photograph of Side Spring discharge shows a slightly larger delta and a different bank shape, but it is still impossible to discern the groundwater impact on the stream (Figure 5). Using the digital photo image, the thermal infrared camera documented the impact of Side Spring which closely mimics the delta in size and shape but the cooler water from the spring is skewed slightly downstream (Figure 5). The temperature measured in the spring was $21^{\circ} \mathrm{C}$ while the camera measured a temperature of $23.5^{\circ} \mathrm{C}$ using the Cold Spot feature of the camera.

\section{Discussion}

Using temperature to study groundwater/stream interactions relies on contrasts. Therefore, seasons and diel conditions are important. The specific conductance data complimented and supplemented the effects seen by the temperature data and were helpful when temperature contrasts were not large. Specific conductance values were generally greater in the groundwater than the surface water and therefore correlated with the groundwater temperatures. Bowles et al. (2006) found that densities of Jollyville Plateau salamanders (Eurycea tonkawae) were significantly higher where specific conductance of the water was lower but the lower specific conductance values in their study were similar to the higher specific conductance values in this study. The Bowles et al. (2006) study compared springs from developed and un-
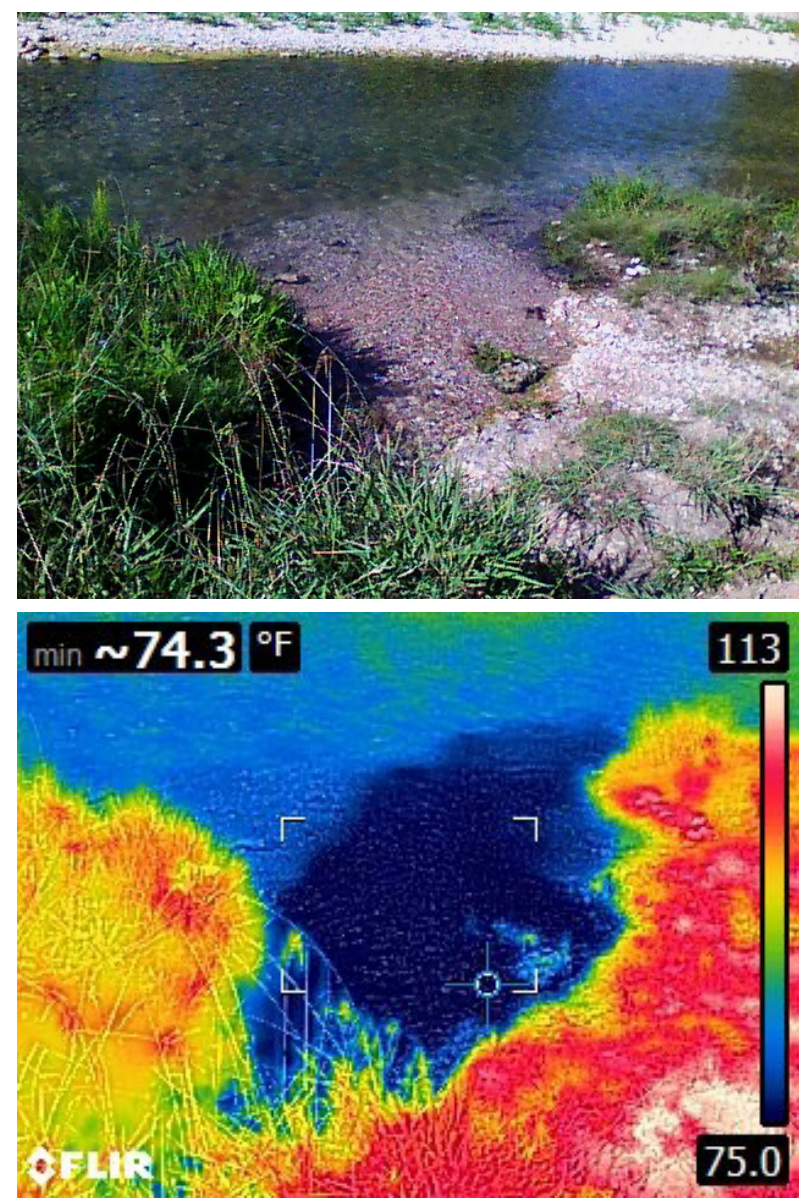

Figure 5. Images of Side Spring August 10, 2016, 4:57 p.m. The top image is a digital photo of Side Spring discharge into Salado Creek and the bottom image is the thermal image of Side Spring showing cooler groundwater (blve colors) entering Salado Creek and continuing downstream along the bank. 